Laboratorio de Arte,4-1991 http://dx.doi.org/10.12795/LA.1991.i04.17

\title{
ESTEBAN SÁNCHEZ FALCONETE, ALARIFE DE LA CATEDRAL
}

\author{
por Fernando Cruz Isidoro
}

Figura prácticamente desconocida para la Historia del Arte sevillano, su nombre fue recogido tímidamente por López Martínez en su obra "Arquitectos, escultores y pintores vecinos de Sevilla", insertando una única noticia documental, que además, no transcribe en su totalidad por no prestarle mayor importancia, limitándose a su simple enunciado ${ }^{1}$.

Cuando nos planteamos el estudio del arquitecto sevillano Pedro Sánchez Falconete, inmediatamente intuimos su posible relación filial con Esteban, lo que tras confirmarse, nos hizo interesarnos por su personalidad. Aunque en nuestra monografía sobre este arquitecto ya esbozamos brevemente los datos inéditos recopilados sobre su padre, el hallazgo de nuevos y el deseo de desarrollar más ampliamente los publicados, nos parece motivo suficiente para dedicarle estas breves líneas que tratan de bosquejar su biografía ${ }^{2}$.

Su actividad laboral como maestro albañil y alarife de là Catedral de Sevilla se desarrolló durante casi medio siglo, al lado de arquitectos tan importantes como Asensio de Maeda, Miguel de Zumárraga, o su propio hijo Pedro Sánchez Falconete, convirtiéndose en el colaborador directo de todos ellos, en quien podían confiar plenamente la construcción de un edificio, levantando con sus propias manos varias de las obras trazadas por los mismos.

1. LÓPEZ MARTÍNEZ, Celestino: Arquitectos, escultores y pintores vecinos de Sevilla. Sevilla, 1928, p. 179.

2. CRUZ ISIDORO, Fernando: El arquitecto sevillano Pedro Sánchez Falconete. En ARTE HISPALENSE, n. ${ }^{2}$ 55. Sevilla, 1991, pp. 13-15. 
Desconocemos la fecha de su nacimiento y si éste aconteció en Sevilla. La primera noticia familiar que poseemos se refiere a la partida de bautismo de su hijo Pedro Sánchez Falconete, fechada en once de enero de 1587 en la parroquia de Santa Cruz de esta ciudad, por la que conocemos el nombre de su esposa y la collación en que vivían. No podemos precisar si éste fue el primer hijo del matrimonio formado por Esteban Sánchez Falconete y María de Mata, ya que tuvieron al menos tres vástagos, pues aparte del varón hemos encontrado datos de dos hijas, una de las cuales llevaba el mismo nombre de su madre. Por estas fechas, hacía ya varios años que pertenecía a la nómina de la Catedral como maestro albañil según se desprende de la documentación, ya que en 1626 se afirma que llevaba cincuenta años trabajando para la institución, por tanto debió entrar al servicio de la misma aproximadamente a mediados de la década de 1570. Su formación profesional tuvo un carácter eminentemente práctico, desarrollada junto a los arquitectos anteriormente señalados, en el ambiente constructivo sevillano de la segunda mitad del siglo XVI, formado fundamentalmente por maestros albañiles. Esta pericia y destreza técnica hábilmente aprendida de la experiencia diaria logró transmitirla posteriormente con gran acierto a su hijo Pedro, que siempre hizo gala de este buen oficio.

A partir de 1588, la vida de la familia fue muy ajetreada. A principios de ese año, la Catedral le encargó la realización de unas importantes obras de reedificación en la vivienda y molino de la dehesa de Doña María, en la villa de Dos Hermanas, de las cuales se conservan numerosas certificaciones y memorias de gastos realizados. Los trabajos se iniciaron en enero de ese mismo año, feneciendo a principios del mes de agosto. De la construcción se encargó personalmente Esteban, quien asimismo se ocupó de las tareas administrativas, contratando el personal y comprando lo necesario, empleando en estos menesteres y en supervisar el acarreo de los materiales desde la capital, 180 días, que le fueron pagados aparte. En la memoria que Esteban certificó en Sevilla, el 23 de noviembre de 1588 -una vez acabada la obra-, hizo relación por menor de los gastos de materiales, sueldos y portes, con un coste total que ascendió a 122.287 maravedíes. De la misma se desprende como se utilizaron más de 69 carretadas de piedra, otras 68 entre piedra y madera (la mayoría suministradas por Francisco Parejo, así como buena parte de los otros elementos de la construcción), más de 8.000 ladrillos, más de 3.000 tejas, 11 cargas de yeso, 99 cahices de cal, 240 cargas de barro, 47 cargas de varetas, varias docenas de tablas... ${ }^{3}$. Las obras fueron tasadas minuciosamente por el maestro mayor de la Catedral, Asensio de Maeda, en 152.882 mrs. y consistieron en "el subido y asiento y enzarzado y

3. "Memoria de lo que he gastado yo Estevan Sanchez Falconete en la obra que se ha hecho en la dehesa de Dona Maria en materiales y en portes de materiales y en otras cosas necesarias para la dicha obra". Archivo de la Catedral de Sevilla (en adelante A.C.S.), Contaduría, caja 20 (sección sin inventariar). 
tejado de las piezas que ay en lo que se a ydificado de nuevo"; tapias de calzamiento y de tabiques; dos chimeneas; cítaras de ladrillos; caballetes; cerramientos; la cubierta de alfarje del molino; encalado de todo el edificio; puertas; ventanas; pesebres; enmaderado del molino y hechura de la viga del molino y noria... Además de las dos sumas anteriores, se le debían a Falconete los 180 días que se ocupó en "traer los materiales" que a 3 Rs./día, supusieron 540 Rs., así como una gratificación de otros 200 Rs. que se le entregaron. Todo esto montó 300.299 mrs., pero como a Esteban se le habían anticipado por el maestro mayor 244.868 mrs., sólo se le libró el resto el 17 de diciembre de 1588 , es decir, 55.431 mrs. ${ }^{4}$.

Apenas concluida esta obra, se le envió a la villa de Carmona para que levantase el edificio de una cilla que la institución catedralicia pensaba erigir para almacenaje de los diezmos de la zona. Las trazas y condiciones fueron dadas de manera conjunta por Asensio de Maeda y Esteban, quienes para este fin se trasladaron en mula a esta localidad, dibujando planta de la misma (que se conserva en el archivo catedralicio) ${ }^{5}$, empleando en estos cometidos y en el ir y venir tres días, por lo que Esteban cobró 1.122 mrs. Al confiársele la construcción se vio en la necesidad de desmontar su hogar sevillano y trasladarse con su familia, empleando cinco días en la mudanza "en llevar su casa y trato" y en la ingrata tarea de "haçer desembaraçar las casas y hechar la gente fuera dellas para començar a hacer la cilla" (en concreto fueron dos vecinos). Por los gastos del transporte efectuado por un carretero le fueron librados 62 Rs. Inmediatamente se inició la edificación, que fue administrada por Manuel Azedo ${ }^{6}$. Su sueldo como maestro albañil fue de medio ducado por día de trabajo (5 1/2 Rs.), lo que le permitió una economía de cierto desahogo, lo suficiente como para mantener criado (Pedro Fernández), quien también trabajó en la obra ${ }^{7}$. La fábrica de la cilla se hizo cargo del alquiler de la casa que tomó en Carmona, así como de proporcionarle cabalgadura cada vez que era requerido por los canónigos para informar sobre el estado de la construcción, teniendo constancia de que al menos fue solicitado tres veces ${ }^{8}$. Finalizada la obra regresa a la capital, certificando el 23 de agosto de 1589 haber recibido 40 Rs. para "pagar dos carritos por llevar mi

4. "Tasasion de la obra de albañeria que a hecho Esteban Sanchez Falconete en el ydificio y casa que el cabildo de la Santa Yglesia mando hazer en la dehesa de Doña Maria la qual es la siguiente" (rubricada por Asensio de Maeda). A.C.S., Contaduría, caja 20 (sec. sin inventariar).

5. LUNA FERNÁNDEZ-ARAMBURU, Rocío y SERRANO BARBERÁN, Concepción: Planos y Dibujos del Archivo de la Catedral de Sevilla. Sevilla, 1984, p. 102. A.C.S., Fondo Histórico General (en adelante F.H.G.), caja $90, \mathrm{n}^{\mathrm{9}} \mathrm{4}$.

6. Certificación de Sánchez Falconete y Azedo del 10 de octubre de 1588. A.C.S., F.H.G., caja 91, n.o 1.

7. Nómina 3." que comenzó el 29-VIII y terminó el 3-IX de 1588. A.C.S., F.H.G., caja 91, n.ำ1.

8. Certificaciones rubricadas por Falconete el 22 -VI-1589 por 51 Rs. y $12 \mathrm{mrs}$., y el 22 -VIII-1589 de 25 Rs. y 24 mrs., por el alquiler, y del 3-[X-1588, por la cabalgadura. A.C.S., F.H.G., caja 91, n.ำ 1. 
casa a Sevilla" ". Sin embargo, pronto fue requerido para la ampliación de ese edificio, informando junto a Maeda en marzo de 1590, sobre las condiciones a seguir para la ejecución de la "casa de la cilla de Carmona", con seguridad para vivienda del administrador. Esta vez emplearon cuatro días en estos cometidos (conservándose igualmente la planta que trazaron), cobrando en esta ocasión $1.088 \mathrm{mrs}$. que le fueron librados por orden de su compadre el chantre D. Antonio Pimentel, el 30 de marzo. Fue Asensio de Maeda quien se encargó de comprar la casa vieja sobre cuyo solar se levantó la nueva, así como una partida de ladrillos y cal, abonándosele por tal motivo el 17 de abril del mismo año 34.000 mrs.; Juan Fagundez se ocupó de demoler el edificio y de guardar los materiales servibles; a Diego Pérez se le entregaron 30 ducados por otra partida de cal, ladrillos y tejas. La obra fue finalmente valorada en 1.000 ducados, haciéndose cargo de su ejecución el maestro albañil Cristóbal González ayudado por el carpintero Juan Gutiérrez Padilla ${ }^{10}$. Este edificio se conserva actualmente, aunque bastante transformado por los diferentes usos que ha tenido.

Inmediatamente vuelve a trasladarse, esta vez a Sanlúcar de Barrameda, para ocuparse de la reforma de las bodegas y cilla que la Catedral Hispalense renovó en esta importante localidad gaditana. Nuevamente le acompañó su familia, gastando "en llevar su casa a Sanct Lucar y bolberla a Sevilla" con posterioridad, 100 Rs., 30 de los cuales se los entregó el maestro mayor. Las obras se ejecutaron a lo largo de 1590, e igualmente fueron trazadas por Asensio de Maeda, quien para este fin permaneció en la villa seis días a finales de 1589 , volviendo en repetidas ocasiones para supervisar el estado de las mismas, cobrando en conjunto "por los biajes" 13.532 mrs. ". Los materiales fueron suministrados por Maeda $^{12}$ y Miguel de Gainza ${ }^{13}$, empleándose 200 cahices de cal, 15.000 ladrillos y tejas, 550 tablas, 55 carretadas de madera y 108 "terciadas"..., montando todo 506.962 mrs., cantidad a la que se rebajó la suma de $22.644 \mathrm{mrs}$. por la

9. A.C.S., F.H.G., caja 91, n. ${ }^{0} 1$.

10. "Memoria de lo que se va gastando en la casa de la cilla de Carmona -empeçose esta obra a veinte y seis de março de 1591". A.C.S., F.H.G., caja 91, n. ${ }^{2}$ 1. En el cabildo del 20-II-1657, se ordenó escribir a la ciudad de Carmona solicitando se mandase cerrar e incorporar a la cilla una calleja que lindaba con ésta, to que fue pronto atendido, ya que en el cabildo del 24-III-1657, la Catedral decidió dar las gracias a la villa por "aver dado la calleja". A.C.S., Actas Capitulares (en adelante Ac. Cap.) de los años 1657-58, n." 64, fol. 13 vto. y 19.

11. El 5-XII-1589 se libraron a Maeda, 5.304 mrs. "por el tiempo que se ocupo en San Lucar a yr a traçar las bodegas"; el 7-V-1590, 5.236 mrs. por otros 7 días, y el 13-IX-1590, 2.992 mrs. por 4 días. A.C.S., Contaduría, caja 22 (sec. sin inventariar).

12. El 26-IV-1590, Maeda certificó haber recibido de D. Antonio Pimentel, 1.300 Rs. "para mercar materiales para la obra" (ladrillos, madera y cal) y el 26-VI-1590, 201 1/2 Rs. de 5.000 clavos "de tillado" y 5 arrobas de almagra. A.C.S., Contaduría, caja 22 (sec. sin inventariar).

13. Certificaciones de pago de Maeda a Miguel de Gainza el 14-IX-1590 por 8.000 tejas y 2.500 ladrillos, y del 4-XI-1590 por 3.000 tejas. Diego Cance, mercader de maderas, certificó el 23-XI-1590, haber recibido de D. Antonio Pimentel, 23 ducados por el flete de maderas desde Sevilla. A.C.S., Contaduría, caja 22 (sec. sin inventariar) 
venta de las tinajas y maderas viejas de la anterior construcción, siendo por tanto el coste total de 484.318 mrs., más 5.478 mrs. que se debían al maestro mayor ${ }^{14}$. El 23 de febrero de 1590, Esteban Sánchez Falconete certificó haber recibido 51 Rs. "de menoscabo" por las herramientas de su propiedad empleadas ${ }^{15}$, constando documentalmente como última nómina que se le pagó, y que supone por tanto el fin de la obra, la fechada el 12 de enero de 1591 , de 57 Rs. ${ }^{16}$, regresando inmediatamente a Sevilla. Este edificio se hallaba en la ribera o barrio bajo de la villa, entre las calles actuales de Carmen y Carril de los Angeles, conservando su función de depósito de diezmos hasta que su estado ruinoso, a mediados del siglo XVIII, determinó la construcción de una nueva cilla en el barrio alto ${ }^{17}$.

De tono similar es su participación en la localidad sevillana de Utrera en la ejecución de un edificio destinado igualmente a recoger los diezmos, en el que también debió intervenir dictando las condiciones el maestro mayor. Lo cierto es que la obra quedó en manos de Esteban, quien labró más de lo establecido, ordenándose en el cabildo del 14 de diciembre de 1592, que a Falconete se le librasen 20 ducados por cuenta de la fábrica "por remuneración de la perdida que a hecho en la obra que hizo en Utrera" ${ }^{18}$.

Hacia 1595, encontramos a la familia Sánchez Falconete asentada en la collación sevillana de San Juan de la Palma, concretamente en la calle Piernas -actual Pedro Miguel-, citándose a Esteban como testigo en favor del Duque de Alcalá, en el pleito que éste mantenía con el Marqués de Villanueva del Río por la posesión del Palacio de las Dueñas, exponiendo el primero como circunstancia a su favor las diversas reformas efectuadas en el edificio, señalando entre los artífices a Esteban Sánchez Falconete, sin que podamos precisar en que consistieron las obras que quedaron a su cargo ${ }^{19}$.

Cuatro años más tarde, el 9 de julio de 1599, arrienda junto a su mujer, María de Mata, unas casas de por vida pertenecientes a la Catedral en la calle de la Rabeta -Moratín-, en el barrio de la Magdalena. En el contrato ante el escribano público Gaspar de León se fijó un alquiler de 3.350 mrs. y 13 gallinas anuales ${ }^{20}$. Tratábase de la tercera casa a mano derecha yendo de la Pajería -Zaragoza- a la plazuela de los Comitres, lindante por una parte con casas propiedad del Hospital

\footnotetext{
14. "En 15 de febrero de 1591. Quenta de la cilla y bodegas de S. Lucar de barrameda y las que della resultan". A.C.S., Contaduría, caja 22 (sec. s/inv.).

15. Idem.

16. Durante la obra se pagaron "37 nóminas de los peones y oficiales" con un coste de 196.127 mrs. (nóminas semanales). Ver nota 14.

17. BARBADILlo DELGADO, Pedro: Historia de la ciudad de Sanlúcar de Barrameda. Cádiz, 1942. Reproducción facsímil, pp. 376-377.

18. A.C.S., Ac. Cap. de los años 1592-93, n. ${ }^{9} 39$, fol. 47.

19. Dato facilitado por D. Teodoro Falcón Márquez. Archivo Ducal de Medinaceli, legajo 26.

20. A.C.S., Mesa Capitular (en adelante M. Cap.) 1493 (20), fol. 413.
} 
de la Misericordia, y por otra con una calleja sin salida donde abrían unos postigos de casas que salían a la calle Catalanes -Carlos Cañal- ${ }^{21}$. Un apeamiento más antiguo de esta vivienda nos describe sus calidades, que serían muy similares por estas fechas; tras flanquear el umbral, se accedía a la casa-puerta, verdadero centro de la morada y su pieza más importante, donde se desarrollaba gran parte de la vida familiar; a ella abría la cocina con su chimenea, que a su vez daba paso (a su derecha) a un pesebre con un pajar pequeño; en la casapuerta se disponía una escalera realizada en ladrillo para subir a la planta alta o soberado, donde se encontraban los dormitorios, techándose una parte del edificio con cobertura de ladrillo por tabla sobre cuatro vigas que soportaban una azotea pisable con pretil, a la que se accedía por una escalera de madera, mientras que otra zona de la casa presentaba un tejado a un agua sobre tres vigas; la vivienda era tan alta como ancha ${ }^{22}$.

Podemos imaginarnos su vida familiar en estos años transcurriendo apaciblemente y con cierto desahogo, siendo acompañado al trabajo por su hijo Pedro desde los 12 ó 14 años, quien iba asimilando paulatinamente sus enseñanzas, sintiendo Esteban el natural orgullo paterno al ver cómo su hijo iba alcanzando progresivamente los diferentes escalones de su oficio, hasta primero igualarlo en renombre y más tarde superarlo.

Como maestro albañil de plantilla de la Catedral, Esteban aparece reflejado en los libros de Mayordomía de Fábrica desde 1597 hasta 1626, cobrando como complemento a su salario diario la cantidad anual de 10.200 mrs. (300 Rs.) ${ }^{23}$.

El 17 de enero de 1602 firmó recibo ante el mayordomo de la mesa capitular, Juan Gallardo de Céspedes, de 748 mrs. en pago de dos días que se ocupó en la visita del donadío del Pulgar, que tenía Alonso Jiménez de Ledezma ${ }^{24}$.

Muy interesante es la memoria de obras, también fechada en enero de 1602, en la que especifica al por menor los gastos que tuvo en el reparo de la casa de Andrés Franco, "que estava incorporada al Candilejo", que puede ser buena muestra de su actividad en este área. Especifica como tardó tres días en el arreglo (a 7 Rs./día, 21 Rs.), empleando cinco peones (que cobraron cada uno 4 Rs./día), utilizando 2 cargas de yeso (cuyo coste fue de 24 Rs.) y montando el transporte de 24 cargas de cal y ladrillos, una escalera de caja, "unos pedaços de tablas y unos palos para quicios", 14 Rs., ascendiendo todo a 82 Rs., más otros 2, por la saca de tierra y basura. El libramiento fue ordenado por el citado mayordomo el 19 de dicho mes ${ }^{25}$.

21. A.C.S., M. Cap. 1495 (22), fol. 380 vto

22. A.C.S., M. Cap. 1501 (28), fol. 239 vto.

23. $\mathrm{Y}$ asimismo en A.C.S., libros de Nóminas y Salarios de $1602, \mathrm{n} .{ }^{9} 325$, fol. 132; y de los años 1618-25, n.으. 326 , fol. 123 vto.

24. A.C.S., Contaduría, caja 31 (sec. s/inv.).

25. Idem. 
En el cabildo del 29 de noviembre de 1602, presidido por D. Luciano de Negrón, se decidió aumentarle su jornal diario a 7 Rs., sueldo aceptable para la época ${ }^{26}$. A esta.función añadió por orden capitular de 16 de mayo de 1603 -muy probablemente a instancias de su compadre, D. Antonio Pimentel, que presidió la reunión- el nombramiento de alarife albañil, aunque sin remuneración, ya que el cargo lo ocupaba todavía Miguel de Zumárraga, pero que le supuso, en definitiva, un importante jalón en su ascenso profesional que posteriormente legaría a su hijo ${ }^{27}$. No fue sino hasta 17 años más tarde, en el cabildo del 3 de julio de 1620 , cuando se le nombró de pleno derecho en la plaza "en la forma y de la manera que Miguel de Zumárraga lo servía", ordenándose asimismo que le acompañase en las visitas, como alarife carpintero, Francisco López ${ }^{28}$.

La primera referencia que tenemos de su actividad como alarife se produjo el primero de agosto de 1603, cuando junto a Miguel de Zumárraga visitó los "marcos del agua" en Alcalá de Guadaira, efectuando diversas mediciones y arreglos y colocando un título sobre los mismos. Acompañaron en calidad de peritos de la Catedral a los diputados nombrados por ésta y por la ciudad, el canónigo doctor Bartolomé Olalla de Rojas y el jurado Alonso Leandro de $\mathrm{He}$ rrera, respectivamente, en la visita que efectuaron para dilucidar el pleito que ambas instituciones mantenían sobre el uso del agua en la huerta de Santa Marta de la mencionada localidad. En el informe certificado por el canónigo y rubricado además por Zumárraga y Falconete, indica como dentro de la huerta existía una cueva que atravesaba por debajo del "camino real", con una distancia desde su boca hasta la atarjea del agua de 43 varas menos cuarta, encontrando una vez dentro a las 12 varas y dos tercias un primer manantial, a las 26 y tres cuartas un segundo, y a las 32 y media tercia un tercero, todos ellos pertenecientes a la huerta. Declara como la atarjea tenía en su losa un agujero tapado con mezcla, lo que impedía que la huerta recibiera el agua, comprobando como había sido la ciudad y no la Catedral la que robaba el caudal, por lo que se ordenó que con un martillo y una daga se destapase, levantando sobre ella una cítara de ladrillo en lugar de un tablón podrido que tenía ${ }^{29}$.

El 23 de mayo de 1603 se le comisionó por el cabildo para hacer rematar la obra que era necesaria efectuar en los molinos y casas del canónigo Salcedo, que muy probablemente él mismo habría apreciado con anterioridad ${ }^{30}$.

La salida del año 1604 fue realmente aciaga para su reposada vida familiar, tristemente ensombrecida por la muerte de su esposa y de una de sus hijas, y la

\footnotetext{
26. A.C.S., Ac. Cap. de los años 1599-1602, n. ${ }^{2} 42$, fol. 112 vto.

27. A.C.S., Ac. Cap. del año 1603, n. ${ }^{2} 43$, fol. 4.

28. A.C.S., Ac. Cap. de los años 1619-20, n. ${ }^{50}$, fol. 92; Nóminas y Salarios de los años 1618-25, n.. ${ }^{9} 326$, fol. 7

29. A.C.S., F.H.G., caja $80, n^{9} 1$.

30. A.C.S., Ac. Cap. del año 1603, n. ${ }^{2} 43$, fol. 14 vto.
} vto. 
enfermedad de otro hijo, lo que le supuso un auténtico trauma. De realmente dramática puede calificarse la carta rubricada que envió al cabildo Catedral enumerando las desgracias que le habían acontecido "que a sido dios servirme por mis pecados", señalando que su mujer -María de Mata- se había matado accidentalmente al caerse de una escalera (citamos como su casa de la Magdalena poseía dos), y como en la misma semana se produjo el fallecimiento de una de sus hijas (no indica la causa o enfermedad), "toda esta desgracia dentro de seis dias", y además haber enfermado otro hijo -¿Pedro?-, quien se encontraba en cama, expresando amargamente cómo se había quedado sin dinero para hacer frente a tantos infortunios "estoi tan pobre y necesitado", y no tener ya nada más de valor que vender "pues ya no tengo alhaja que venda", por todo lo cual suplicaba le socorriesen con alguna ayuda monetaria "que en ello hara V S. servicio a dios nuestro señor". Su petición fue leída en el cabildo del 5 de enero de 1605 presidido por el canónigo D. Luciano de Negrón, quien resolvió concederle de inmediato 20 ducados "por esta vez" 31.

Sin embargo, pronto tuvo que sobreponerse y volver a sus ocupaciones habituales, empeñado en constantes visitas a las posesiones de la Catedral y en sus reparos. De pocos meses más tarde es la noticia que hemos recogido, exponente de su trabajo diario; se trata de una carta de pago expedida por el mayordomo Juan Gallardo a Esteban, por los dos días que se ocupó en visitar la casa del Cortijo de Mudapelo, apreciando los arreglos que eran necesarios y en "atajarlos", por lo que cobró 32 Rs. (suma bastante elevada para el escaso tiempo empleado), que le fueron entregados el 23 de abril de $1605^{32}$.

En ese mismo año se encargó de la reparación de los tejados de unas bodegas en Bormujos, efectuada a instancias de los señores contadores de la Catedral. De la obra se conserva una memoria de gastos que refleja las intervenciones acometidas y los costes de materiales y mano de obra. Empleó 450 tejas, 1 cahíz de cal, 4 cargas de arena, 2 medias vigas, 32 canalones, 130 clavos...; un maestro albañil y cuatro peones trabajaron en los tejados cuatro días, un carpintero y otros cinco hombres sanearon las maderas de puertas y pasamanos, mientras que otros siete peones ayudaron en otros menesteres, costando el arreglo 376 Rs. ${ }^{33}$. El 19 de septiembre de 1605 rubricó carta de pago al mayordomo de la mesa capitular, Juan Carrasco, por 100 Rs. "que se le dan para reparar los tejados de la bodega que el cavildo tiene en Bormujos" ${ }^{34}$, recibiendo el 19 de noviembre $6.625 \mathrm{mrs}$. a cuenta de $12.765 \mathrm{mrs}$. "que montaron los gastos" 35 .

\footnotetext{
31. A.C.S., Contaduría, caja 33 (sec. s/inv.).

32. Idem

33. Memoria fechada el 2-X-1605. Idem.

34. Certificación rubricada. Idem.

35. Certificación rubricada. Idem.
} 
En el cabildo del 16 de enero de 1609 se apremió a los alarifes de la Catedral para que junto a los del Municipio, apeasen la casa del veintenero Carvajal, en Cal de Bayona -Federico Sánchez Bedoya-y posteriormente entregasen el informe, que Falconete debió efectuar ${ }^{36}$.

El 1 de febrero de 1613 le fueron abonados 72 Rs. por el mayordomo Miguel Noguera, por las condiciones que entregó para el arreglo de la cilla malagueña de Teba ${ }^{37}$.

Más interesante y fruto de su buena labor constructiva es su participación al frente de diversas obras realizadas en edificios religiosos, que ponen de manifiesto su reputada fama en la ciudad como maestro albañil. El primero de agosto de 1609 hizo tasación y condiciones para la ejecución de cuatro celdas que se habían de construir en el convento sevillano de monjas de la Concepción "titulado de Santas Justa y Rufina”, y según López Martínez, que transcribe parcialmente la noticia, Esteban se denomina a sí mismo ampulosamente "maestro mayor de obras de la Santa Yglesia" ${ }^{38}$, algo incierto, ya que lo era en la práctica -que no por título- Miguel de Zumárraga. A fines del verano de 1614 se ocupó de dar las condiciones y reparar la iglesia de la villa de Albaida, empleando en la labor y en el "yr estar y bolver", tres días, por lo que el mayordomo Miguel Noguera le expidió el 24 de septiembre del mismo año 816 mrs., que Esteban certificó haber recibido seis días más tarde ${ }^{39}$.

Desde hacía varios años, su hijo Pedro se había independizado laboral y afectivamente, lo que motivó que Esteban decidiera traspasar la titularidad de su casa de la Rabeta a su hija María de Mata. El contrato se firmó ante el escribano público Gaspar de León el 15 de septiembre de 1611, por la vida de ésta y del primer marido que tuviese, aumentándosele la renta en $5 \mathrm{mrs}$. más anuales ${ }^{40}$. Al parecer, ésta nunca llegó a casarse, por cuanto que en la renovación periódica de informes sobre esta vivienda sigue manteniéndose esta misma fórmula jurídica, conservándola hasta su muerte, siendo al parecer también utilizada por su hermano Pedro y su familia, a cuyo cargo debió quedar María tras el fallecimiento de su padre, si no se desposó ${ }^{41}$.

Desde 1614, los datos laborales recopilados se refieren fundamentalmente a sus funciones de alarife de la Santa Iglesia, tarea que desempeñó conjuntamente con el maestro carpintero Francisco López, realizando las visitas y apeamientos que le fueron encomendados y que recogemos en notas ${ }^{42}$, cuyos derechos, libra-

36. A.C.S., Ac. Cap. de los años 1609-10, n. ${ }^{2} 45$, fol. 3 vto.

37. Certificación rubricada. A.C.S., Contaduría, caja 40 (sec. s/inv.).

38. LÓPEZ MARTÍNEZ, Celestino: Arquitectos, escultores... P. 179.

39. A.C.S., Mayordomía, caja 41 -A (sec. s/inv.).

40. A.C.S., M. Cap. 1493 (20), fol. 413.

41. A.C.S., M. Cap. 1494 (21), fol. 42; 1495 (22), fol. 380 vto.

42. - Sevilla, 13-IX-1613, ante el escribano Dionisio Riquelme, de unas casas en la collación de San "Elizondo", que vacaron por muerte de D. ․ María de Monroy y R.․ de Mendoza, que lindaban con la pósada de la Cruz. A.C.S., F.H.G., caja 69, n. ${ }^{9} 1$. 
dos en tres tercios a lo largo del año, montaron en 16232.550 mrs. y en 1624 2.952 mrs. $^{43}$.

Otras dos referencias de interés menor, pero que muestran su quehacer por estos años, fue la libranza a su nombre, de 8 Rs., efectuada en febrero de 1615 a cuenta de 2 cargas de yeso que empleó en alguna obra sin especificar ${ }^{44}$, y la visita y aprecio que llevó a cabo en julio de 1621, de un pinar y una bodega de Utrera, que le ocuparon dos días y por lo que se le abonaron el 29 del citado mes 816 mrs. $^{45}$.

A fines de 1624, encontrándose viejo y con muchos achaques, propuso a la Catedral que su hijo le sustituyese en su trabajo, pensando sin duda que era el medio más apropiado para que éste heredase su cargo en esta institución y le sirviese de base para escalar un más alto puesto, hasta llegar a ejercer la tan ansiada Maestría Mayor de la misma, su propia aspiración frustrada y que su hijo finalmente alcanzó años después, aunque él ya no tendría la satisfacción de ver. El nombramiento de Pedro como su sustituto en el oficio de alarife se produjo el 24 de enero de 1625, sin sueldo, "con las obligaciones que Esteban Sánchez Falconete su padre lo servía a quien por su vejez y enfermedades se a excusado deste cuidado", y "goze del mismo salario despues de los dias de su padre" ${ }^{46}$.

Apartado de las tareas constructivas y de alarife -que fueron desempeñadas de inmediato por su hijo-, su muerte se produjo a fines de julio o en los primeros días de agosto de 1626 , minada su salud muy probablemente, por las penurias y

- San Juan de Aznalfarache, 27-X-1613, ante Dionisio Riquelme, de unas casas y bodega que vacaron por muerte del arcediano de Reina, César Raimundo. A.C.S., F.H.G., caja 80, n.ำ 15, $15 / 1$.

- Sevilla, 14-VII-1621, ante Dionisio Riquelme, de unas casas que vacaron por muerte de Fco. Ruiz y su mujer Juana de Barrera, lindantes con casas del barbero Gaspar Esteban (padre del pintor Murillo). A.C.S., F.H.G., caja 112, n. ${ }^{2} 18,18 / 1$.

- Sevilla, 26-VIII-1621, ante Dionisio Riquelme, de unas casas principales en la calle Abades que el racionero Sebastián Pérez de Helguera dejó vacantes por muerte y se pusieron en cabeza de su sobrina D. a Marina Godo de Helguera, que lindaban con la esquina de la calle de la Botica de las Aguas. A.C.S., F.H.G., caja 86, n. $^{9} 4$.

- Sevilla, 26-VIII-1621, ante Dionisio Riquelme, de unas casas en la calle Abades, sacadas de la principal anterior, sitas en una barreruela sin salida, que tenía el racionero y se pusieron en cabeza de su sobrina. A.C.S., F.H.G., caja 86, n. ${ }^{\circ} 4$.

- Sevilla, 4-V-1623, ante Dionisio Riquelme, de unas casas en la calle de Abades que se quitaron a Juan Fco. Roso por defecto de fianza, que lindaban con casas del Conde de Olivares. A.C.S., Mayordomía, caja 41 -A (sec. s/inv.).

- Sevilla, 13-VII-1624, ante Dionisio Riquelme, de unas casas en la collación de Santiago el Viejo, que tenía Bemardino de Isla. A.C.S., F.H.G., caja 100, n. ${ }^{9} 58,58 / 3$.

43. A.C.S., Mayordomía de Fábrica del año 1623 , n. ${ }^{\circ} 137$, fol. 5 , lib. 50 y fol. 9, lib. 128; del año 1624, n. 98 , fol. 12 vto., lib. 119 , fol. 18 , lib. 120 y fol. 20 vto., lib. 244.

44. A.C.S., Mayordomía de Fábrica del año $1615, n^{9}{ }^{9} 130$, fol. 1 vto.

45. A.C.S., Mayordomía de Fábrica del año 1621 , n.ำ 135 , fol. 7 , lib. 187.

46. CRUZ ISIDORO, Fernando: El arquitecto sevillano... P. 23. Del mismo autor: Pareceres y aprecios en la Sevilla del segundo tercio del siglo XVII. En revista de historia del arte ATRIO n.9 3, pp. 41-49. Sevilla, 1991. A.C.S., Ac. Cap. de los años 1624-25, n.ำ 52, fol. 68 vto.; Nóminas y Salarios de los años 1618-25, n.ำ 326, fol. 7 vto. y 123 vto. 
calamidades que sufrió la población sevillana en ese año como consecuencia de las secuelas que provocó la inundación. De su entierro se ocupó la Catedral, delegando en D. Luis Sirman, a quien en el cabildo del 16 de agosto de ese año, presidido por D. Diego de Guzmán, se ordenó se le librase lo que hubiera gastado en el funeral, atentos a los buenos servicios prestados por Esteban Sánchez Falconete "maestro albañil que a servido 50 años a la fabrica", limosna que salió de la hacienda de la fábrica ${ }^{47}$. 


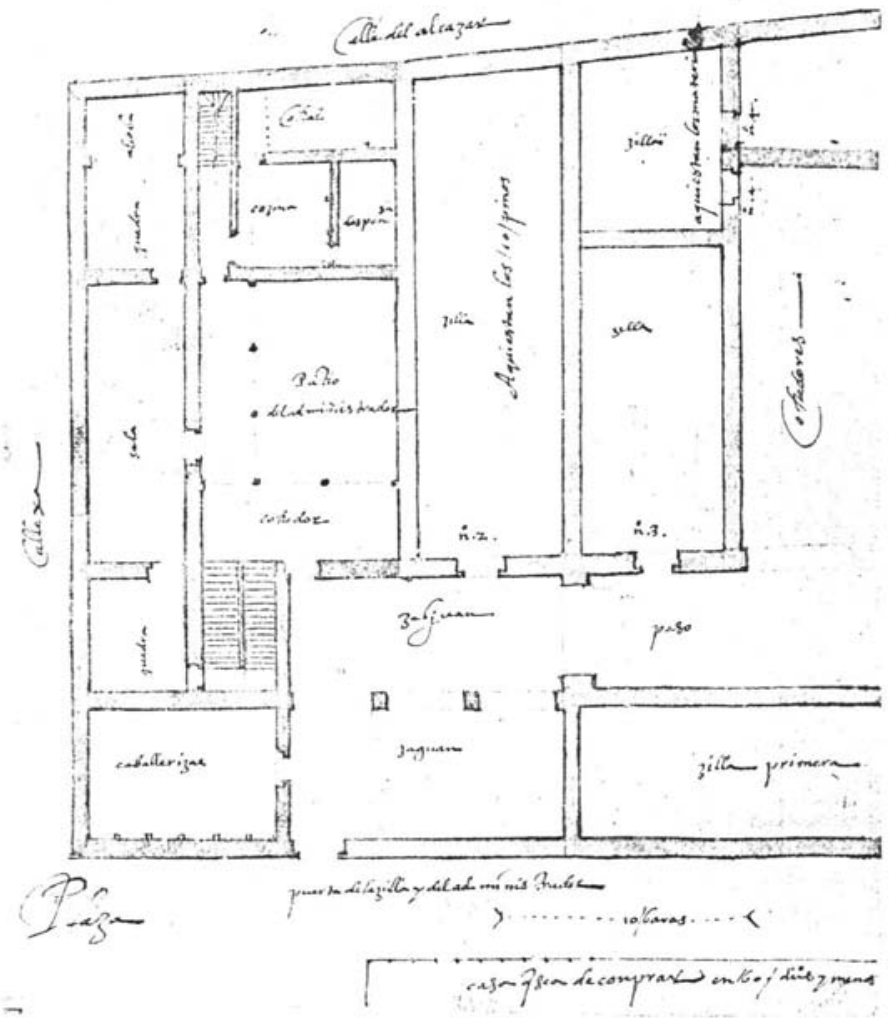

Figura 1

Planta de la vivienda que para el administrador de las rentas decimales se levantó en la cilla de Carmona. 


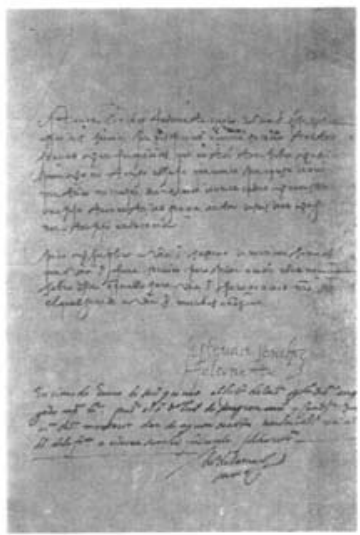

Figura 2

Canta rubricada por Esteban Sánchez Falconete informando al cabildo de la Catedral hispalense de la muene de su esposa y de una hija y de ta enfermedad de otro hijo.

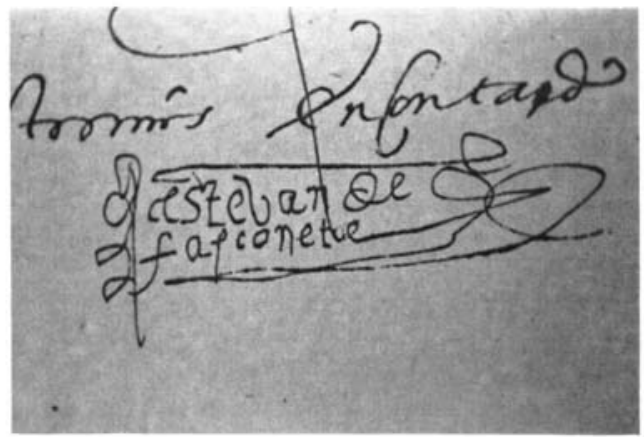

Figura 3

Firma habitual de Esteban Sánchez Falconete. 